\title{
Decision Making of Third-party Logistics Based on Analytic Hierarchy Process
}

\author{
Shixia Duan ${ }^{1}$ and Min $\mathrm{Xu}^{1}$ \\ ${ }^{1}$ Department of Management Engineering, Zhengzhou University, Science Avenue, Zhengzhou city of Henan, \\ China \\ duanshixia@zzu.edu.cn,252681554@qq.com
}

Keywords: TPL; core competence; AHP; quantitative analysis; evaluation system

\begin{abstract}
Nowadays, the logistics industry is developing rapidly, and becoming more perfect, therefore, more and more enterprises are facing the new decision in developing and growing: whether or not to entrust their internal logistics business to the professional third-party logistics companies. So it is necessary to build a scientific and effective evaluation system to solve this problem. In this paper, based on the comprehensive analysis of the factors affecting this decision, the evaluation index system of decision-making for the third-party logistics is constructed by using AHP, and experts are invited to mark the indexes for comprehensive evaluation to help enterprises effectively solve this
\end{abstract} decision-making problem.

\section{INTRODUCTION}

With the rapid development of the market, logistics business has gradually occupied an increasingly high status, and some enterprises even regard it as their core competitiveness, and there are also more and more third-party logistics enterprises in the market at the same time. As a result, how to develop logistics business quickly, safely and efficiently has become an urgent problem for enterprises (Jun, Chen\&Bangzhong, Wang, 2009). In general, there are two ways to solve this problem, they are respectively retaining the logistics business and contracting it to a third-party logistics enterprise. For the decision of whether or not to choose a third-party logistics (TPL), enterprises need to consider the problem from their own perspective and the entire logistics industry, so this is a very complex work. Because there are many factors involved, it is likely to cause decision-making mistakes, then bring serious consequences to the enterprise, once the judgment is not accurate.

At present, the methods commonly used to judge the decision-making for the third- party logistics include expert judgment, Delphi method and so on. However, there is not a complete set of scientific and perfect systems to evaluate the problem synthetically with the industry yet, so it is difficult for enterprises to make correct and scientific decisions. In view of this, This paper will start with AHP which is used widely, then construct an evaluation index system of decision-making for the third-party logistics, and combine the expert scoring method to help enterprises make quantitative analysis of this decision-making problem scientifically.

\section{THE MEANING OF THE THIRD-PARTY LOGISTICS}

The third-party logistics is not only a kind of enterprise, but also a new mode of logistics operation and management. The enterprises which mainly focus on making products and daily operations will entrust their logistics business to a professional third-party logistics enterprise with a contract for some restrictive conditions or in the interest of concentrating on the main business, and build a perfect information system with the third-party logistics enterprise at the same time. The owner enterprise only needs to maintain close contact with the logistics enterprise through the information system, so as to carry on the entire process management and the control (Qiangguo, Ouyang\&Xiaobing, Cheng\&Daoping, Wang, 2010).If an enterprise decides to entrust its logistics business to a third-party logistics enterprise, it will save a great deal of cost. But at the end of the day, which kind of logistics and transportation modes to choose is never determined by the subjective will of the enterprise, but effective evaluation methods considered with many objective conditions. This paper will use analytic hierarchy process to make decision.

\section{DECISION CONDITIONS OF THE THIRD-PARTY LOGISTICS}

Along with the development of the third-party logistics enterprise, in order to determine whether the enterprise should choose a third-party logistics service, it is necessary to analyze the advantages and disadvantages that the third-party logistics may bring, and carry on concrete analysis according to enterprise' own conditions (Lan, Liu, 2005). The traditional decision-making basis is mainly to see whether the enterprise has the ability to carry out their own logistics business. If the enterprise has the ability, technology and funds, then self-employed, but in this case, the cost is usually considered less, but in reality, the cost is also an important factor which affect whether the enterprise choose the third party logistics (Yu, Tian\&Guohua, Gong, 2000). To solve this decision problem, this paper will consider from the following four key points.

\subsection{The core competence of the enterprise}

Each mature enterprise has its own core competitiveness. After making clear its core resources, the enterprise can build its own capacity system and form 
its own competitive advantages by considering synthetically its internal environment and external environment. In the same conditions as others, If the enterprise has competitive advantage in the logistics ability, then it is more suitable for it to retain the logistics business and then maximize the competitive advantage (Zhigang, Song, 2011). For example, JD's self-built logistics. In addition, if the enterprise's ability to manage the logistics business is stronger, the logistics competition advantage is more competitive than other enterprises, then the availability of enterprise self logistics is relatively large.

\subsection{The strategic position of logistics in supply chain}

In different industries, and for different products, the requirements for the logistics business are not the same, so the logistics business will be is in different position. The higher the demand is, the higher the position of logistics is. For those industries in which product is more various, which contact with the end consumer more closely, and which service is stronger, logistics business occupies the core value status, such as supermarkets, coal, consumer goods and so on. For an enterprise, if the logistics business occupies a core value position in its own industry, no matter self-run or outsourced, it can control the upstream business and downstream consumers so as to bring long-term interests to itself as long as the enterprises can carry out scientific and effective management of this link (Hanming, Chen, 2011).

\subsection{Economic feasibility of using third party logistics}

Costs and benefits will come into being when the enterprise entrusts the logistics business to a third-party logistics service provider. But if the cost is too high, and the benefit of outsourcing logistics is not enough to make up for the cost, then choosing the third-party logistics is obviously not feasible. Therefore, enterprises should make economic feasibility analysis of the third-party logistics from two aspects of cost and benefit in the process of decision-making (Xueyong, Gao\&Ni, Li\&Silong, Feng, 2013). Consideration should be given to fixed costs, variable costs (including personnel salaries, operating expenses, expenses paid by logistics enterprises, management fees, expenses, and other temporary logistics expenses and so on.), the direct economic benefits brought by the adoption of the model of third-party logistics service, economic benefits of time savings and economic benefits of enhancing logistics operation capability.

\subsection{Sunk costs and disposal costs of employees}

Under the planned economy system, all the industrial and commercial enterprises own the logistics, thus forming a larger stock of the logistics facilities. When the production retail enterprises intend to withdraw from the logistics field and take the logistics outsourcing, their logistics facilities are difficult or can only be transferred at a low price, which brings huge sunk costs to enterprises, and forms a higher exit barrier.

The work of some departments within the enterprise is likely to be replaced by third party logistics because of looking for outsourcing logistics. In addition, supply chain logistics is usually integrated with other services such as finance, marketing, or manufacturing. This will lead to a number of organizational, administrative and practical issues for some of the actual business including integration of transportation and warehousing. In addition, the integration of the company's internal information system makes it difficult to turn the logistics business to the third party logistics company.

\section{APPLICATION OF AHP IN DECISION MAKING OF THIRD-PARTY LOGISTICS}

\subsection{Constructing evaluation index system}

The first step of the analytic hierarchy process is to construct the evaluation index system. When there is a complex decision problem, the total target can be decomposed into several multiple objectives, and then the several small targets will be further decomposed into several multiple targets, those are key indicators that affect the decision result, then an feasible scheme can finally be put up base on those indicators. In this way, a complex decision problem is decomposed into a closed system with several levels, which is a process from top to bottom. The factors on the same layer have influence on the upper layer factors and be influenced by the factors on lower layer at the same time (Long, Zeng, 2013). On the basis of the above analysis, this paper puts forward the flow chart of the third party logistics selection decision, as shown in Figure 1, and constructs the evaluation index system, as shown in figure 2 .

\subsection{Establish evaluation matrix}

Although there are many indicators affecting the decision making, but the degree of influence of each index is different, that is, the degree of importance to the upper layer target. To judge the relative importance of each index, it is necessary to invite experienced experts in the industry to compare the indicators 2 by 2 and then to grade them. All the sub goals of each sub objective constitute a judgment matrix. In determining whether or not to select the third-party logistics, determine to invite 8 experts to make a comprehensive evaluation of the importance of the $i$ th element relative to the $j$ th element, and use the symbol $a_{i j}$ to represent the evaluation value (Zhidong, Shen,2013).The standard of value judgment for $a_{i j}$ is usually assigned with 1-9 scales, as shown in Table 1. 
Table 1: Relative importance quantization scale

\begin{tabular}{|c|c|}
\hline assignment & Importance \\
\hline$a_{i j=1}$ & element ${ }^{i}$ and element $j_{\text {are equally important }}$ \\
\hline$a_{i j=3}$ & element ${ }^{i}$ is a little more important than element $j$ \\
\hline$a_{i j=5}$ & element $i$ is more important than element $j$ \\
\hline$a_{i j=7}$ & element ${ }^{i}$ is much more important than element $j$ \\
\hline$a_{i j}=9$ & element ${ }^{i}$ is extremely more important than element $j$ \\
\hline$A_{i j}=$ Even numbers between 1 and 9 & The importance of element $i$ relative to element $j$ \\
\hline$A_{i j}=1 / 3$ & between adjacent judgments \\
\hline$A_{i j}=1 / 5$ & element $i$ is a little less important than element $j$ \\
\hline$A_{i j}=1 / 7$ & element $i$ is less important than element $j$ \\
\hline$A_{i j=1 / 9}$ & element $i$ is much less important than element $j$ \\
\hline
\end{tabular}

The experts compare the indicators at the same level 2 by 2 and give the judgment of their relative importance. After all the indexes are judged 2 by 2, a comparison judgment matrix will be formed.

\subsection{Index weight judgment and consistency test}

After determining the relative degree of importance of each index according to the evaluation matrix, it is necessary to transform it into the absolute degree of importance of each index relative to its parent's goal, that is, the weight. The single order weight of the evaluation index can be transformed into calculating the eigenvalue and eigenvector of the judgment matrix. specific computational procedure divided into the following five steps:

(1) Determine hierarchy judgment matrix $T$;

(2) Compute the $\mathrm{N}$ root of product of each factor in each row of the judgment matrix.

$$
\overline{w_{i}}=\left(\prod_{j=1}^{n} u_{i j}\right)^{1 / n},(\mathrm{j}=1,2 \ldots \ldots \mathrm{n})
$$

(3) Normalize the vector $\bar{W}=\left[\overline{w_{1}}, \overline{w_{2}}, \ldots \overline{w_{n}}\right]$.

$$
w_{i}=\overline{w_{i}} / \sum_{j=1}^{n} \overline{w_{j}},(\mathrm{j}=1,2 \ldots \ldots \mathrm{n})
$$

$W=\left[w_{1}, w_{2}, \ldots w_{n}\right]$ will be the characteristic vector;

(4) Compute the maximum eigenvalue of judgment matrix $\lambda_{\max }$.

$$
\lambda_{\max }=\frac{1}{n} \sum_{j=1}^{n}(T W)_{j} / w_{j}
$$

$(T W)_{j}$ represents the first $\mathrm{j}$ component of a vector.
(5) Conduct consistency check

The formula for calculating the degree of consistency of matrices is:

$$
C R=\frac{C I}{R I}, C I=\left(\lambda_{\max }-n\right) /(n-1)
$$

For a matrix, if it is fully consistent, then $\lambda_{\max }=n$.but in reality, it is impossible to make the matrix has consistency absolutely in practice. In most instances, the constructed matrix will meet the need as long as it is relatively consistent; that is to say, close to consistency. When $\mathrm{CR}<0.1$, It is assumed that the degree of consistency of matrix A can be accepted, but if $\mathrm{CR} \geq 0.1$,it is assumed that the degree of consistency of the matrix cannot be accepted. This moment, the importance of the element $i$ relative to element $j$ in the matrix needs to be adjusted until the matrix meet the the criteria as $\mathrm{CR}<0.1$ (Haiyan, Wang\&Run, Tang\&Rong, Yu\&Jiyuan, Zheng, 2011). As for the consistency index RI, you can refer to the Table 2.

Table 2: RI index

\begin{tabular}{|c|c|c|c|c|}
\hline $\begin{array}{c}\text { Number of matrix } \\
\text { hierarchy }\end{array}$ & 1 & 2 & 3 & 4 \\
\hline RI & 0 & 0 & 0.52 & 0.89 \\
\hline $\begin{array}{c}\text { Number of matrix } \\
\text { hierarchy }\end{array}$ & 5 & 6 & 7 & 8 \\
\hline RI & 1.12 & 1.26 & 1.36 & 1.41 \\
\hline $\begin{array}{c}\text { Number of matrix } \\
\text { hierarchy }\end{array}$ & 9 & 10 & 11 & 12 \\
\hline RI & 1.46 & 1.49 & 1.52 & 1.54 \\
\hline $\begin{array}{c}\text { Number of matrix } \\
\text { hierarchy }\end{array}$ & 13 & 14 & 15 & \\
\hline RI & 1.54 & 1.58 & 1.59 & \\
\hline
\end{tabular}

\subsection{Compute combination weights}

The combination weight of evaluation index, that is, the weight of each level index in the evaluation index system relative to the total target, is equal to the product 
of the weight coefficient of parent evaluation index and that of its sub generation evaluation index. For example, in Figure 2, suppose that the weight coefficient of the U1 for $\mathrm{U}$ is $a$, and the weight coefficient of the $\mathrm{U} 11$ for $\mathrm{U} 1$ is $b$, then the weight coefficient of the element U11 for the total target $U$ is $a^{*} b$. In this way, the weight coefficient of each element for the total target $U$ is finally obtained.

\subsection{Determine the final options}

When a Enterprises determine whether or not to choose the third-party logistics, it can invite several experts within the industry to grade itself in view of the eight factors in Figure 2, according to the above model and the method of expert scoring method. Sum up the scores after the final score of each factor being multiplied by its weight, then the enterprise's comprehensive score on the third party logistics decision is got. The final score is the gist to determine whether to choose a third-party logistics.

The higher the score shows that it will be more suitable for the enterprise to give its logistics business to the third party logistics enterprises; the lower the score shows that it is more suitable for the enterprise to retain the business.

\section{CONCLUSIONS}

In this paper, the background of the problem is firstly analyzed, and then, the evaluation indexes are determined on the basis of the further analysis of the third-party logistics decision conditions, after that, combining the analytic hierarchy process (AHP), the decision-making about the third-party logistics is discussed deeply, and the corresponding evaluation system is constructed. The result of this research shows that Analytic hierarchy process (AHP) can solve this complex decision problem scientifically and effectively, and it is relatively simple. Firstly, this method decomposes the research object into a system by establishing an evaluation system, which clearly reflects the various influencing factors of the research object, and makes the decision-making process more simple and clear. Secondly, this method combines the experience of experts, and achieves the effective combination of qualitative and quantitative, and improves the accuracy of decision-making. Finally, this method ensures the scientificity of decision making. The subjective experience of experts may be lack of certain rationality, consistency test can correct this deviation, and ensure the rationality and scientific of subjective judgment. Therefore, AHP has multiple advantages in judging the third party logistics decision.

\section{REFERENCES}

[1] Jun, Chen\&Bangzhong, Wang, 2009. Study on the Selection of Third-party Logistics Service Provider Based on AHP, Logistics Sci-Tech. (11), pp.122-123.

[2] Qiangguo, Ouyang\&Xiaobing, Cheng\&Daoping, Wang, 2010. Thoughts on the Development and Direction of the Third-party Logistics in China, Journal of Graduate School of Chinese Academy of Social Sciences. (01), pp.86-89.

[3] Lan, Liu, 2005. Study on the Choice of Third-party Logistics by Enterprises, Scientific Management of Railway Materials. (04), pp.24-25.

[4] Yu, Tian\&Guohua, Gong, 2000. Study on Decision Making for the Third-party Logistics, Logistics technology. (01), pp.33-35.

[5] Zhigang, Song, 2011. Analysis of the Mode of E-commerce Logistics Distribution in China, Enterprise Vitality. (09), pp.46-48.

[6] Hanming, Chen, 2011. Discussion on the Development of the Third-party Logistics in China, Pioneering with Science \& Technology Monthly. (07), pp.35-36.

[7] Xueyong, Gao\&Ni, Li\&Silong, Feng, 2013. How to Improve the Efficiency and Service Quality of Third-party Logistics Enterprises through Informatization, Electronic Test. (05), pp.252-256.

[8] Long, Zeng, 2013. Evaluation on land use efficiency Based on AHP -- a case study of Yingjiang District in Anqing City, Contemporary Economics. (15), pp.126-128.

[9] Zhidong, Shen,2013. Construction of Performance Evaluation System of State Owned Enterprises by AHP, Auditing Research. (02), pp.106-112.

[10] Haiyan, Wang\&Run, Tang\&Rong, Yu\&Jiyuan, Zheng, 2011. Research on Performance Evaluation System of Urban Public Transport Industry, China Industrial Economics. (03), pp.68-77 
Figure 1: Flow chart of decision making of third-party logistics

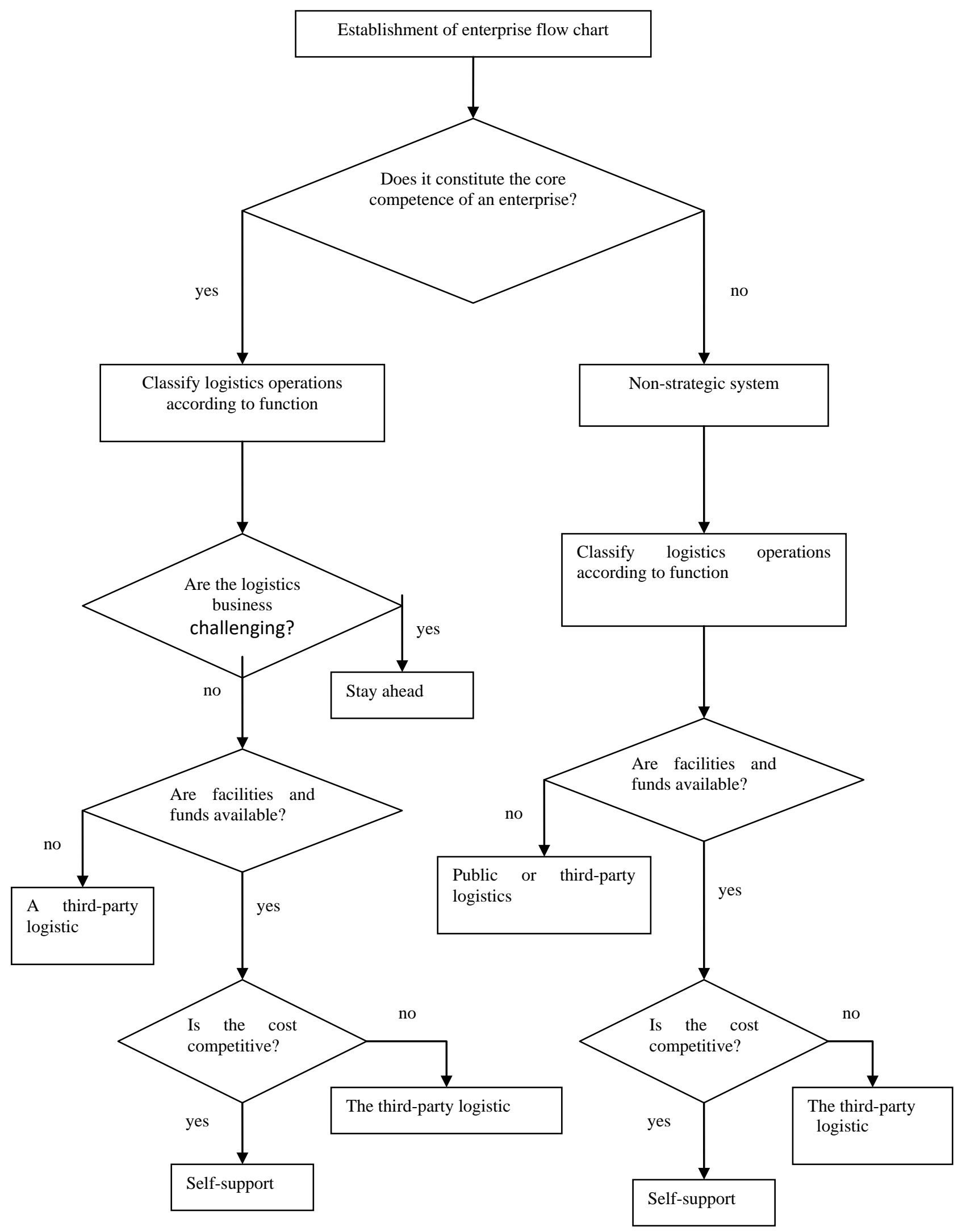


Figure 2: Evaluation index system

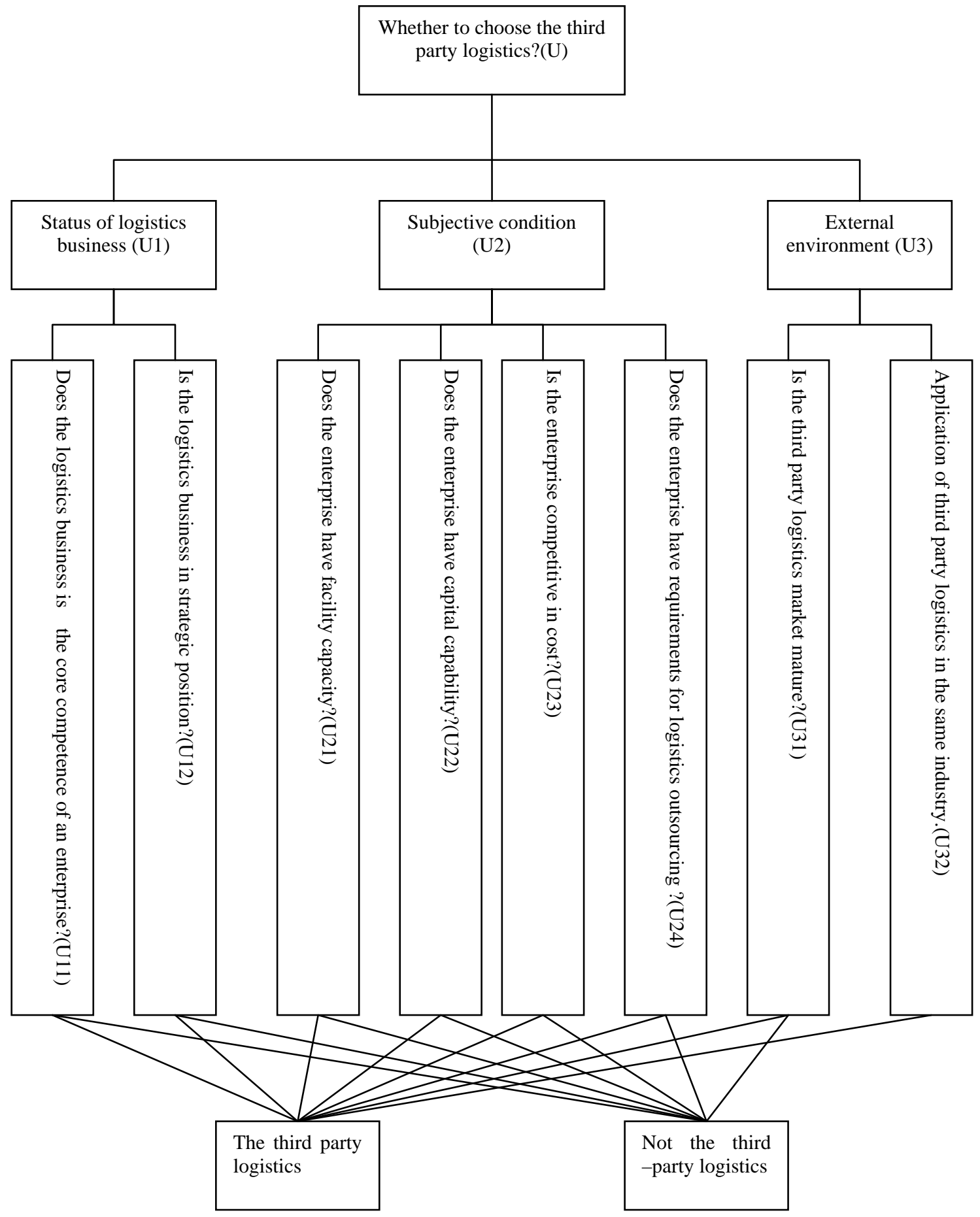

